\title{
A CLÍNICA PSICANALÍTICA NA UNIVERSIDADE: REFLEXÔES A PARTIR DO TRABALHO DE SUPERVISÃO
}

\author{
Nadja Nara Barbosa Pinheiro* \\ Vinicius Anciães Darriba**
}

\section{RESUMO}

Partindo do trabalho como supervisores de estágio acadêmico, desenvolvido em uma clínica-escola do curso de graduação em psicologia, levantam-se questóes pertinentes à condução de processos clínicos, fundados na perspectiva psicanalítica, nesses ambientes. É confrontado o lugar do saber e do sujeito na universidade e na psicanálise como elementos que fundam uma ética que é própria a esta - questionando, com isso, alguns efeitos aí produzidos sobre a inserção do aluno no campo psicanalítico e a possibilidade de sua transmissão pelo trabalho de supervisão. Privilegiando os efeitos suscitados pela imposição de um prazo para o encerramento dos atendimentos clínicos desenvolvidos no estágio, o posicionamento freudiano frente a esse dispositivo é tomado como paradigma da posição do analista frente aos impasses que lhe são apresentados no exercício de seu trabalho.

Palavras-chave: clínica psicanalítica; supervisão; universidade.

\section{Abstract \\ PSYCHOANALYTICAL CLINIC AT UNIVERSITIES: NOTES FROM THE PRACTICE OF "CONTROL-ANALYSIS"}

Supported by their practice as supervisors of Psychology graduating students, the authors bring up some questions related to psychoanalytical clinic at Universities. Two elements which fund psychoanalytical ethic are confronted: the place of knowledge and the place of subject at University and at Psychoanalysis. From that, it is questioned the insertion of the students in psychoanalytic field as well as the possibilities of its transmission be made though out an experience

* Doutora em Psicologia Clínica. Professora Adjunta do Departamento de Psicologia da Universidade Federal do Paraná. Pesquisadora do Laboratório de Psicanálise (UFPR).

** Doutor em Teoria Psicanalítica. Professor Adjunto do Departamento de Psicologia da Universidade Federal do Paraná. Pesquisador do Laboratório de Psicanálise (UFPR). 
of "control-analysis". By focusing on the effects produced by the imposition of a deadline on clinical treatment, the authors took Freud's clinical directions as a paradigm of analyst's position in order to face some clinical difficulties.

Keywords: psychoanalytical clinic; control-analysis; university.

Ao ocupar a posição de docente na universidade, o psicanalista tem diante de si questões das quais não deve recuar. Qual é a possibilidade de operar neste contexto a partir de uma ética que é própria à psicanálise? Como o discurso universitário incide no que se propõe ali como o ensino da psicanálise? Para uma prática clínica que, na atividade do estágio, se pretende referenciar pela psicanálise, quais as consequências de se encontrar inserida entre as atividades formativas exigidas para a obtenção de um título de graduação' ${ }^{1}$ ? Embora entendamos que tais questôes andem juntas, partiremos aqui da última delas, privilegiando nossa experiência como supervisores de acadêmicos de psicologia que tomam como fundamento teórico a psicanálise.

Os problemas que a relação entre a psicanálise e a universidade apresentam, e que já eram considerados por Freud ([1919] 1990), dão ensejo a uma extensa produção bibliográfica. Esta ocorre predominantemente no campo da psicanálise e, mais acentuadamente, a partir da demarcação por Lacan ([1969-1970] 1992) da diferença entre um discurso universitário e um discurso do analista. Tal diferença, inserida no que se designou como a teoria dos quatro discursos ${ }^{2}$, estabelece-se grandemente em termos do lugar que o saber ocupa em um e noutro discurso. Ou ainda, em termos da relação do sujeito ao saber que um e outro discurso configuram.

Partindo, mais genericamente, desta diferença na relação ao saber, que não é sem consequências para a práxis do psicanalista na universidade, localizaremos algumas particularidades da psicanálise neste contexto, cujos efeitos mais agudos entendemos se pronunciarem na prática clínica dos estágios que supervisionamos. Em primeiro lugar, é preciso considerar que a prática clínica se apresenta aos estudantes como uma exigência curricular. Ou seja, ela está necessariamente associada a condições que não dizem respeito à práxis da psicanálise como: (1) a obrigatoriedade da frequência à supervisão, (2) atribuição de um conceito para fins de aprovação ou não do estudante na disciplina de estágio. Entendemos que a vigência de tais condiçôes faz com que a prática clínica, em tal contexto, corra $o$ grande risco de submergir na lógica da formação acadêmica, independentemente do modo como atue o supervisor. 
Mais importante ainda é considerar que a chegada dos estudantes à clínica, incluídos aí os que escolhem a psicanálise como referencial teórico, os que escolhem um psicanalista como supervisor, prescinde de um percurso de análise pessoal. Não é da posição de analisante que se chega à clínica, mas da posição de estudante. Também aí se imprime sobre essa experiência uma marca que, em alguma medida, independe de um ou outro estudante já ter buscado uma análise, ou se ver incitado a fazê-lo no decorrer do estágio.

Finalmente, nos voltaremos, no presente estudo, para uma peculiaridade da prática clínica realizada no estágio: o encerramento deste último determina o término dos atendimentos realizados pelo estagiário ${ }^{3}$. Ou seja, a duração dos atendimentos é delimitada pelo calendário acadêmico. Não tomaremos este fato no sentido de apontar sua impropriedade para a psicanálise. O que nos interessa investigar é que tipo de manejo se encontra, por parte dos estagiários, frente ao desfecho dos atendimentos assim determinado. Nossas observaçōes prévias, a partir da experiência da supervisão, sugerem que, neste momento em que os atendimentos têm que ser encerrados, os impasses advindos da diferença entre o lugar do estudante na universidade e o lugar do analista na clínica são mais facilmente localizáveis.

Verificamos que os estagiários se veem convocados a ocupar um lugar distinto daquele que a universidade lhes demanda ao longo de sua formação. Os efeitos deste lugar de estudante se tornam visíveis em sua face impeditiva de uma condução clínica da situação. Examinaremos, neste artigo, como isto se encontra nas diferentes modalidades de resposta apresentadas pelos estagiários.

Propomos aqui, então, uma reflexão crítica do lugar de supervisor da prática clínica no estágio, acerca das incidências neste dos impasses que pontuam a relação entre a psicanálise e a universidade. Reflexão que se voltará para este momento particular do encerramento dos atendimentos. Preocupa-nos, no entanto, que a discussão, assim ensejada, leve simplesmente à conclusão de que nada que faça jus a levar o nome de psicanálise possa ter lugar na universidade.

Diferentemente dos que possam asseverar isso, entendemos que, para além da evidência dos impasses existentes, é preciso se perguntar qual é a clínica possível, a partir da psicanálise, neste contexto. Até porque tal clínica, que se organiza em torno do nome da psicanálise, mostra-se relevante em seus efeitos junto a pacientes e estagiários: seja em termos do estabelecimento do desejo de inserção no campo da psicanálise, seja em termos da confirmação deste desejo, quando já previamente manifestado, ou, ainda, nas transformaçôes subjetivas apresentadas pelos estagiários e pelos pacientes.

A questão que ora propomos sobre a conceituação do que pode ser a clínica (psicanalítica) do estágio abre um campo extenso e pouco explorado. De nossa 
parte, entraremos neste terreno a partir, justamente, do que aqui destacamos nesta experiência: a contingência de o término do atendimento já estar previsto. Tomando a experiência freudiana como paradigmática, partiremos em nossas reflexões do modo como, no caso clínico do "Homem dos lobos" ([1918] 1990), Freud respondeu à imposição de um prazo para o término do atendimento que vinha desenvolvendo. O autor faz, em "Análise terminável e interminável” ([1937] 1990), considerações teóricas em consonância com sua proposição de 1918. Tal experiência nos sustentará na compreensão do que a nossa experiência, como supervisores, vem nos apresentando e questionando.

\section{A INCIDÊNCIA DO DISCURSO UNIVERSITÁRIO NA CLÍNICA DO ESTÁGIO: O LUGAR DO SABER, O SUJEITO DIVIDIDO E A ORIENTAÇÃO POR UMA ÉTICA}

Partindo do modo particular como se dá o encerramento dos atendimentos nos estágios, ao qual nos referimos, propomos efetuar algumas reflexões acerca dos efeitos sobre o estagiário. Nossa experiência vem demonstrando que, neste momento, o estagiário se vê convocado a ocupar um lugar distinto do que lhe foi demandado, até então, ao longo do curso de graduação. Este momento é profícuo, no sentido de identificar, no contexto clínico do estágio, a incidência do que, em Lacan ([1969-1970] 1992), vemos designado como discurso universitário. Ao mesmo tempo, é quando fica claro que este último se atualiza como impasse ao se tentar sustentar, pela psicanálise, o exercício da clínica no estágio.

É fácil observar que, na universidade, os alunos são impelidos a assumirem a suposição da existência de um saber que se oferece à acumulação e à possibilidade de anteceder a condução do fazer prático. A psicanálise, por seu lado, se define pela sustentação de algo irredutível ao saber. O saber, portanto, é parcial, não-todo, provisório e, fundamentalmente, não precede a prática clínica. Tudo isso, vale dizer, não apontando, na psicanálise, para a insuficiência de um saber por cujo progresso trabalharíamos na universidade. Trata-se antes do próprio limite ao saber que a psicanálise desvela, na medida em que toma o sujeito como se constituindo sobre um fundo de desamparo que se revela incontornável.

O que tem o sentido de uma insuficiência para o estudante orientado pelo discurso universitário fala, na psicanálise, do impossível ao qual o saber se dirige. Não se trata de recobri-lo com mais um saber ao qual o estudante é convocado - o que é tomado na via de uma impotência -, mas de incluí-lo como impossível mesmo, cujo manejo não se faz do lugar do saber. Freud ([1937] 1990) já 
percebia seu ofício como impossível, em acréscimo ao educar e ao governar ${ }^{4}$. Impossível no sentido de um não-acabamento que é consequência de se pretender aí aceder à verdade. Esta, reportando-se ao desamparo fundamental do sujeito, jamais estará subsumida ao saber, o qual sempre se mostrará parcial na tentativa de dizê-la.

No momento de conclusão do estágio, momento de encerramento dos atendimentos até então conduzidos pelo estagiário, este se vê confrontado ao que usualmente se designa como "encaminhamento". O que nos chama a atenção no modo do estagiário se posicionar frente a essa tarefa é a busca de uma solução de continuidade. Isto pode se dar pela oferta de que o paciente permaneça na instituição aos cuidados de outro estagiário; ou ainda, quando isso se faz possível, de que o paciente continue as sessões com o mesmo estagiário em outro espaço. Sem entrar no mérito da pertinência de tais oferecimentos para que o trabalho clínico possa ter continuidade, queremos destacar que, do lado do estagiário e não necessariamente do paciente, tais encaminhamentos são tomados como uma passagem através da qual o corte que está em jogo pode ser contornado, sem deixar resto.

Entendemos que tal aspiração a um "fechamento" (outro termo corrente no âmbito dos estágios clínicos na universidade) sem resto - por exemplo, sem uma significação de abandono para o paciente - fala de uma demanda que é aquela que se endereça ao estudante na universidade. Diante desta situação, como de qualquer outra, ele deve ser capaz de recorrer a um saber que, sendo corretamente aplicado, dê conta. Seu saber pretende, neste caso, se escrever como um "saber fazer não sofrer a perda”. No entanto, as opções tendo sido dadas, a decisão a ser tomada parece ser do paciente. Observamos que a decisão crucial é do estagiário, em responder a uma eventual demanda de análise do paciente. Demanda esta que não se confunde mais com a da chegada à instituição, pois se dirige, agora, àquele que está diante dele. Entre dois tempos, não mais estudante e ainda não analista, ele se vê convocado a responder do lugar de sujeito. Isto só se fará possível em dissonância com o discurso universitário, acolhendo a falência do saber que este momento engaja.

O saber aí não mascara mais a divisão do sujeito. Se, no discurso universitário, a tomada da palavra fica condicionada a uma determinada aquisição de saber que a autorize (Lacan, [1969-1970] 1992), na psicanálise não há como responder desde o lugar de sujeito sem que a divisão compareça. A psicanálise revela que o saber, que vem em socorro ao estudante, não exclui o sujeito dividido. Não há algo como um sujeito da ciência que a universidade produziria. O que Lacan nos indica é que o sujeito de que a psicanálise trata não é este que se concebe, na universidade, como 
produto do movimento progressivo inesgotável de tudo situar sob a égide do saber (Lo Bianco, 2006). Para responder do lugar de sujeito, é preciso, justamente, se extrair daí o desamparo, atestando o impossível de tudo saber, não tendo que se traduzir pela impotência do estudante em cumprir sua tarefa.

Isto não nos parece ser algo muito fácil para o estagiário, visto que o resultado mais comum é o de certo encerramento do atendimento não em função do término do estágio, mas em função de sua gradativa retirada da cena clínica. Observamos que, recorrentemente, com a aproximação do término do estágio, o estagiário vai se ausentando das sessões, estando ali apenas de "corpo presente", poderíamos dizer. Verificamos, ainda, que tal desinvestimento é acompanhado pelo paciente, que também se ausenta aos poucos, vagarosamente. Ausência essa que, curiosamente, se expressa, por vezes, nos termos de uma melhora declarada em relação a seus sintomas. Longe de ser tomado como reflexo do trabalho que estaria sendo feito, o relato de uma melhora se presta aí a poupar trabalho, o que faz pensar tratar-se da resposta a uma demanda que se insinua nesta direção. Não por acaso, outra categoria sempre lembrada no âmbito da clínica do estágio é a "alta", o "dar alta" se apresentando como uma das possibilidades de conclusão.

Há vezes, no entanto, em que a aproximação do término do atendimento tem implicações no sentido oposto. O paciente retoma seus sintomas, requerendo do estagiário sua presença, demandando deste um posicionamento quanto ao seu desejo de estar ali sustentando o trabalho. Se isto não for tomado como um resto a ser desconsiderado, ou reinserido na lógica que vimos reger a clínica do estágio na universidade, o estagiário se verá convocado a responder de outro lugar. Essa resposta não mais se sustenta no recurso ao saber de seus estudos, à sabedoria de seu supervisor, ou aos estereótipos que, na cultura, preenchem de conteúdo este lugar. Trata-se de verificar que de nenhum deles virão as garantias que certifiquem a resposta.

Tem-se, a partir daí, que suportar responder de um lugar que o saber não informa. O que só se sustenta nos termos de uma ética que inclui esta dimensão do impossível, não de uma técnica que se presta justamente a obturá-la. Aí se encontra a singularidade e a radicalidade do que a psicanálise circunscreve no campo da clínica. É o desejo de que algo disso encontre, na práxis do estágio, possibilidade de transmissão que faz com que nela nos incluamos como supervisores. Buscaremos, abaixo, elementos na obra de Freud para seguir com a reflexão sobre a clínica do estágio. Estaremos interessados, daqui em diante, menos em localizar as incidências do discurso universitário do que em interrogar a sustentação dessa clínica pela psicanálise. 


\section{UMA CLÍNICA PSICANALÍTICA NA UNIVERSIDADE É POSSÍVEL?}

O percurso que destacamos acima nos fez indicar que a incidência do discurso universitário na prática clínica, quando proposta do lugar da psicanálise, produz marcações importantes e incontornáveis em três elementos específicos. Primeiramente, o lugar do saber que confronta o estagiário impele-o a responder de posições contraditórias e assimétricas. Desse posicionamento, o estagiário se vê compelido a responder a partir da confrontação com sua própria divisão subjetiva. Por fim, tais especificidades revelam aquilo que da psicanálise a orienta por uma ética que a singulariza.

Nossa intenção, a partir de agora, será a de, partindo desses três elementos, refletirmos sobre o percurso freudiano, tomando-o como paradigmático na condução clínica psicanalítica. Sabendo que nos textos de Freud não o encontraremos às voltas com uma experiência clínica similar à nossa (uma clínica que transcorre no interior da universidade), recorreremos, destarte, a um momento clínico específico enfrentado e comentado pelo autor: a imposição de um limite para o término do atendimento. $\mathrm{O}$ posicionamento freudiano será tomado como subsídio teórico/clínico para refletirmos sobre a condução de nosso trabalho na clínica-escola. Poderemos, então, situá-lo no campo da psicanálise, referenciado ao que demarcamos especificar este último: o lugar do saber, o sujeito dividido e a ética que a governa.

Em relação ao estabelecimento de um tempo predeterminado para o encerramento de um processo analítico encontramos, pelo menos, duas passagens específicas na obra de Freud. Nelas, o autor faz menção a este artifício, ora vinculando-o à tentativa de abreviação do tratamento, ora questionando o que poderíamos conceber como sendo o fim de uma análise. O que nos importa salientar é que, em ambos os casos, Freud desvincula a questão do encerramento do tratamento de um possível modelo de cura médica, quer seja este entendido como eliminação dos sintomas ou como resolução definitiva do conflito psíquico. Podemos encontrar tais consideraçôes freudianas tanto em seu texto sobre o "Homem dos lobos" ([1918] 1990) quanto em “Análise terminável e interminável” ([1937] 1990), nos quais o autor é assertivo ao afirmar que devemos inscrever a proposta clínica da psicanálise na singularidade de cada caso.

Nesse sentido, Freud se pergunta sobre a possibilidade de um encerramento do atendimento em termos do estabelecimento de um momento em que se acredita que o paciente se encontra livre o bastante de seus sintomas, inibições e angústias. Assim, se o encerramento esbarra em um limite, o limite se refere à precariedade, parcialidade e transitoriedade do saber que se constrói sobre o inconsciente. Saber 
sempre prestes a se renovar, uma vez que, para Freud, o inconsciente é atemporal e só reconhece um tempo: o presente.

Dessa forma, assinalar um prazo para o encerramento de um tratamento convoca a pensar sobre o limite do analisável e do que pode, em um processo analítico, ser alcançado em termos de saber. Acreditamos que ao esbarrar nesse limite, que se desdobra sobre a clínica, o mesmo deva ser tomado por paciente e analista como uma questão que convoca ao trabalho e não à paralisação. Ou seja, o limite na clínica se refere àquilo que, não sendo da ordem do saber, nos constitui como sujeitos: o desamparo originário que se reatualiza sempre.

A despeito das diferenças (ser uma opção do analista ou uma imposição institucional), acreditamos poder tomar o posicionamento freudiano no caso do "Homem dos lobos" como norteador de nossas reflexôes sobre o estabelecimento de um prazo limite para o encerramento dos atendimentos, tal como ocorre no contexto do estágio. Nossos argumentos se baseiam, sobretudo, no fato de que a posição freudiana frente ao encerramento assinala algo que diz respeito à função do analista no trabalho clínico, naquilo em que esta se relaciona com as possibilidades de desvelamento do inconsciente.

Para Freud, portanto, há necessidade de relacionarmos, na clínica, a tríadetempo, esforço e trabalho psíquico executado, sabendo que o que se alcança em termos de transformação psíquica dependerá do esforço desprendido no ultrapassamento das resistências no campo da transferência. Com isso, o autor inscreve o trabalho da análise na cadeia atemporal dos processos inconscientes, determinando que a função do analista se refira à criação de condições, através do manejo clínico, para a emergência de seus conteúdos.

Este nos parece ser o posicionamento freudiano no caso específico do "Homem dos lobos", quando Freud afirma que, com o passar do tempo, o paciente se tornara extremamente resistente ao progresso do tratamento, recorrendo a resistências cada vez mais eficazes contra os avanços clínicos. É na tentativa de contorná-las que Freud determina um prazo para a conclusão do trabalho. Tal recurso se insere, portanto, no campo do manejo clínico que visa à superação das resistências do paciente ao progresso da análise. Ou seja, o limite estipulado aparece como um recurso para a superação das resistências. Um manejo que, salienta o autor, deve ser necessariamente inserido no seio da transferência. É somente no momento em que esta se apresenta solidamente efetivada, isto é, quando os conteúdos e elementos inconscientes já se apresentam em movimento no espaço clínico, que Freud se permite a imposição de um limite como recurso. Assim o autor nos apresenta tal manejo: "Determinei - mas não antes que houvesse indícios dignos de confiança que me levassem a julgar que chegara o momento certo - que o tratamento seria 
concluído numa determinada data fixa, não importando o quanto houvesse progredido" (Freud, [1918] 1990: 23).

E acrescenta:

Sob a pressão inexorável desse limite fixado, sua resistência e sua fixação na doença cederam e então, num período desproporcionalmente curto, a análise produziu todo o material que tornou possível esclarecer as suas inibiçōes e eliminar os seus sintomas. E também toda a informação que me possibilitou compreender a sua neurose infantil nasceu dessa última etapa do trabalho, durante a qual a resistência desapareceu temporariamente e o paciente dava a impressão de uma lucidez que habitualmente só é obtida através da hipnose (Freud, [1918] 1990: 24).

Conceber o limite temporal como um instrumento que visa à movimentação clínica sugere que o autor estava mais interessado nos desdobramentos clínicos do que em um possível e/ou provável meio de tornar o processo analítico mais breve ou mais eficaz em termos terapêuticos. Parece-nos que Freud objetivava ultrapassar uma resistência peculiar desse paciente, afastando-se de um modo de pensar a clínica psicanalítica pela via da terapêutica breve. Proposta que nos parece ser ratificada pelo autor em "Análise terminável e interminável" ([1937] 1990), quando retoma esse tema para desenvolvê-lo e inscrevê-lo no terreno da ética psicanalítica.

Dando continuidade ao seu posicionamento em face da questão temporal tomado no caso do "Homem dos lobos", Freud relaciona-a com o problema do fim da análise. Ou seja, para o autor, pensar sobre a temporalidade no campo da clínica interessa na medida em que esta se articula às possibilidades de progresso de uma análise e aos obstáculos que a ele se opõem. Entre esses últimos, Freud destaca dois elementos importantíssimos para nossas considerações: a posição subjetiva do próprio analista e o fato de as análises conduzirem ao encontro da castração - rochedo diante do qual o trabalho analítico parece encontrar seu limite. Se levarmos em conta que a castração reatualiza a angústia do desamparo, Freud nos indica que, do lugar do analista, se deve operar para que a análise progrida para além do que se configura intransponível, convocando o paciente ao trabalho psíquico. Não se trata de negar aqui a dimensão do incurável na análise, mas tomá-la não sob o signo da renúncia, e sim como causa para o trabalho.

É desse lugar do analista que Freud responde à imposição de um limite para o término do tratamento no caso do "Homem dos lobos" - na medida em que a resposta que ele forneceu ao impasse foi a proposição de um trabalho. Trabalho que, da parte do paciente, se concretizou através de inúmeras recordações e pro- 
duções oníricas fundamentais para o progresso de seu tratamento. Trabalho que, da parte de Freud, se revelou através de inúmeras construçōes teóricas não apenas reveladoras do conflito singular deste paciente, mas fundamentais para a própria psicanálise.

Se trouxermos para o caso particular da clínica do estágio, acreditamos que é também desse lugar que os estagiários devem responder à imposição de um prazo para o encerramento dos atendimentos. A interrupção do estágio, que neste é decorrente do funcionamento institucional, pode, ainda assim, se fazer mote que convoque ao trabalho e não à paralisação. Ou seja, responder do lugar do analista na sustentação do desejo de mais saber sobre o que se atualiza singularmente em cada encontro clínico é a tarefa que deve ser enfrentada. Do não tudo saber algo ser construído. Porém trata-se, aqui, com a inclusão do impossível de saber como um operador, de um deslocamento da posição de estudante para a posição de analista. A nós, supervisores, cabe a tarefa de acompanhar tais atribuições sem constituir aí um ideal: ensinar a analisar. Afinal, como nos informou o próprio Freud, trata-se de algo impossível.

\section{REFERÊNCIAS}

Darriba, V. A. (2007). Pensando o trabalho de supervisão em psicanálise na universidade. Pulsional Revista de Psicanálise, 1, 32-39.

Freud, S. ([1914] 1918/1990). História de uma neurose infantil. Obras completas, ESB, v. XVII. Rio de Janeiro: Imago.

Freud, S. (1919/1990). Sobre o ensino da psicanálise nas universidades. Obras completas, $E S B$, v. XVII. Rio de Janeiro: Imago.

Freud, S. (1937/1990). Análise terminável e interminável. Obras completas, ESB, v. XXIII. Rio de Janeiro: Imago.

Lacan, J. (1969-1970/1992). O seminário, livro 17: o avesso da psicanálise. Rio de Janeiro: Jorge Zahar.

Lo Bianco, A. C. (2006). Apresentação. In: Lo Bianco, A. C. (Ed.). Freud não explica: a psicanálise nas universidades (pp. 7-8). Rio de Janeiro: Contra Capa.

\section{Notas}

1 Em outro momento, esta questão foi discutida por um dos autores pela via da problematização do trabalho de supervisão psicanalítica na universidade associada à prática do estágio na clíni- 
ca-escola. Darriba, V. A. Pensando o trabalho de supervisão em psicanálise na universidade. Pulsional. Revista de Psicanálise (São Paulo), 1, 32-39, 2007.

2 Os outros dois discursos que Lacan examina são os do mestre e da histérica. Os quatro discursos designam as diferentes modalidades de laço social que o autor identifica na cultura.

3 Em função das particularidades desta experiência, entendemos poder falar de um término do atendimento mesmo que o paciente continue a ser atendido na instituição por outro estagiário ou procure futuramente, em outro espaço, o acadêmico que encerrou o estágio.

4 Somando a estes três o fazer desejar, articulado ao discurso da histérica, Lacan sobrepõe os quatro discursos às operaçóes impossíveis identificadas por Freud (Lacan, [1969-1970] 1992).

Recebido em 17 de março de 2009 Aceito para publicação em 19 de março de 2010 